\title{
Uma reflexão sobre o nu masculino e a rebeldia velada em Almeida Júnior e Alvim Corrêa \\ Rayani Rodrigues Melo' \\ DOI 10.20396/eha.vil4.3488
}

\section{Introdução}

A representação do corpo sempre assumiu um lugar fulcral nas escolas de arte, e representá-lo nu envolveu muitas vezes uma série de tensões, especialmente no século XIX, como aponta Stephanie Dahn Batista, em O Corpo Falante: Narrativas e Inscrições num Corpo Imaginário da Pintura Acadêmica do Século XIX (2011), ao dizer que o nu na segunda metade do século XIX em Paris passava por um momento de negociação entre o mundo particular/sexualizado e o mundo geral idealizado.

As academias de Belas Artes no ocidente, e mais especificamente entre a metade do século XIX e início do século XX (período em que foram pintadas as obras que serão aqui analisadas), possuíam um rigoroso esquema de ensino e prática de desenho de figura humana. No caso da AIBA (Academia Imperial de Belas Artes), que visava aproximar-se do sistema francês de ensino, apresentava um exigente esquema de disciplinas voltadas ao estudo da figura humana, por meio das quais regiam os ideais de beleza da Antiguidade greco-romana. ${ }^{2}$

O presente artigo propõe uma análise comparativa entre duas obras, sendo Derrubador Brasileiro (1871), do artista José Ferraz de Almeida Júnior [1850-1899], e uma aquarela sem título conhecido (1906) do artista Henrique Alvim Corrêa [1876-1910]; visando observar as semelhanças e disparidades que existem entre as duas obras, e consequentemente explorar os temas por elas sugerido.

É preciso salientar que os dois artistas em questão são diferentes em diversos pontos apesar de ambos possuírem nacionalidade brasileira e terem produzido período do fim do século XIX.

Enquanto Almeida Júnior teve seus trabalhos circulando nos meios oficiais de arte e foi também um artista patrocinado pelo império brasileiro, Alvim Corrêa, através de seus desenhos de pequeno formato, curiosamente assinados pelo pseudônimo H. Lemort, sendo estes os que interessam

\footnotetext{
1 Mestranda no programa de pós-graduação em Arte e Cultura Visual, linha A: Imagem, Cultura e Produção de Sentido. Bolsista CNPQ. 2 BATISTA, Stephanie Dahn. Tendências, tabus e transgressões: As academias na Academia Imperial de Belas Artes. Artigo disponível em http://www.cbha.art.br/coloquios/2012/anais/pdfs/artigo_s2_stephaniedahnbatista.pdf.
} 
a esse estudo, parece não ter encontrando um ambiente tão favorável para circulação de seus trabaIhos. Aliás, pouco se sabe sobre os meios por onde os desenhos eróticos de Alvim Corrêa circularam. Hoje eles não encontram-se pendurados nas paredes de importantes museus, tampouco ilustram os livros de história da arte nacional.

Salvo as diferenças, o presente estudo observa o teor erótico presente nos corpos masculinos nas obras de Alvim Corrêa e Almeida Júnior, sendo esse teor o sutil elo de ligação entre ambos.

\section{O corpo erótico em Derrubador Brasileiro (1871) de Almeida Júnior}

José Ferraz Almeida Júnior [1850 - 1899] natural de Itu, São Paulo, foi um pintor reconhecido por trabalhar em suas obras a temática regionalista, até então pouco explorada por seus contemporâneos.

Em 1869, Almeida Júnior ingressou na Academia Imperial de Belas Artes, onde ele seguiu as aulas de Jules Le Chevrel [1810-1872] e de Vitor Meirelles [1832-1910]. Ao concluir os estudos na AIBA, ele retorna para Itu, onde atuou como retratista e professor de pintura. Durante a sua estadia em Paris como aluno bolsista, a mando pessoal de Dom Pedro II, o artista não conseguiu esquecer de sua terra natal e seu gosto pela vida interiorana, já que a "sua ligação com a terra permite-lhe ultrapassar as convenções da Academia e é aparentemente o seu limite"3

A obra intitulada Derrubador Brasileiro (1871), que faz parte hoje do acervo do Museu Nacional de Belas Artes do Rio de Janeiro, nos apresenta um homem sentado acima de uma pedra, em meio a uma paisagem bucólica. No fundo da cena, está representada uma mata semifechada em que podemos identificar típicos elementos da paisagem natural brasileira, como algumas palmeiras que se encontram no canto superior esquerdo da tela, assim como um cacto localizado no canto inferior direito da obra, dentre outras folhagens que preenchem o esquema compositivo da mesma criando uma imagem de uma abundante mata em exploração, paisagem esta comumente encontrada no interior do Brasil no período em que a obra fora elaborada, [Figura 1].

Observa-se sentado acima de uma pedra e com as costas apoiadas em um paredão rochoso um homem que remete à imagem de um trabalhador braçal lidando com a terra.

A figura masculina de Almeida Júnior não se apresenta aqui completamente nua, apesar de ter o sexo bastante realçado pelos contornos sugestivos e dobras do tecido que dão volume na calça.

3 Cf. MICLIACCIO, 2015, p. 28. 


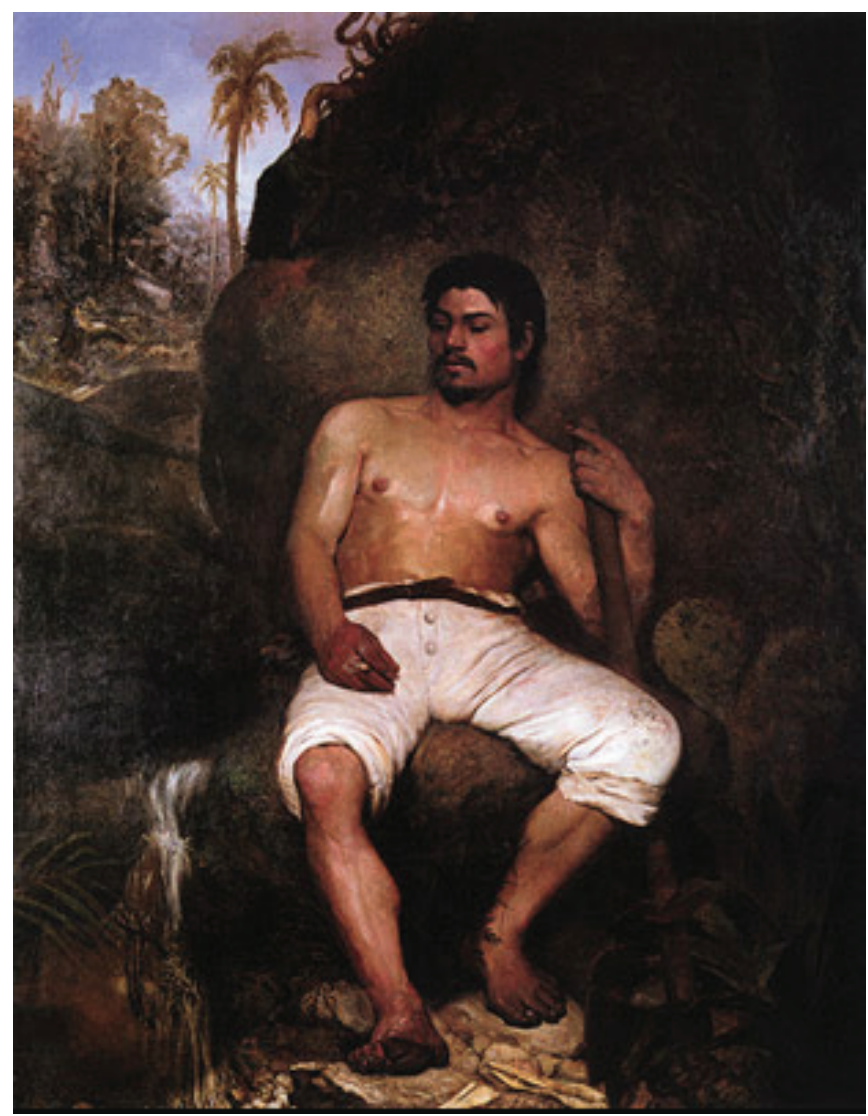

[Figura 1]

José Ferraz de Almeida Júnior, Derrubador Brasileiro, 1871.

Óleo sobre tela, 227 X $182 \mathrm{~cm}$. Museu Nacional de Belas Artes, Rio de Janeiro.

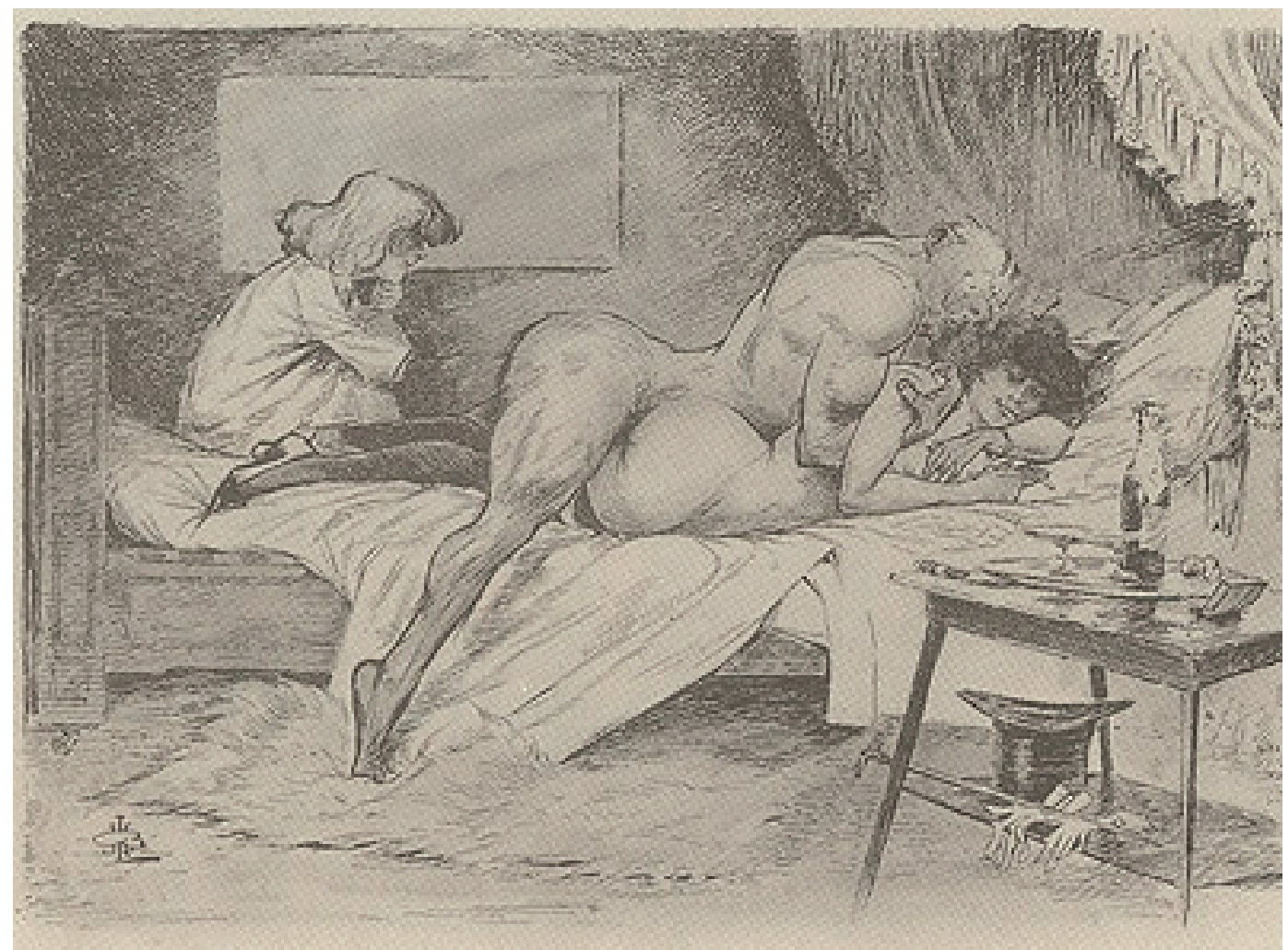

[Figura 2] Alvim Corrêa. Sem Título, 1906.

Lápis, nanquim e aquarela. Sobre papel. 20, 5 cm X 27, 5 cm. Coleção Antônio Maluf, São Paulo 
Esse aspecto não passa despercebido aos olhos mais atentos, e pode até mesmo ser tomado como uma espécie de Punctum da obra, no próprio sentido do termo apresentado por Roland Barthes em A Câmara Clara (1980), pelo qual só alguns detalhes nos emocionam em uma determinada imagem, e que essa característica é o estímulo na fotografia; é o que nos cativa ou o que nos incomoda, ou em outras palavras, é o que nos toca. ${ }^{4}$

A figuração bastante sugestiva do sexo que, embora encoberto pela vestimenta, se manifesta na obra de maneira ressaltada, é um ponto explorado em diversas análises de Derrubador Brasileiro, tais como o relato de Jorge Coli (2002) em seu estudo A Violência Caipira, Stephanie Dahn Batista (2011) em Corpo Falante: Narrativas e Inscrições de um Corpo Imaginário na Pintura Acadêmica do Século XIX, ou ainda José Américo Motta Pessanha (1991) em Despir os Nus. Em todas essas análises, os autores chamam a atenção do leitor para a representação proeminente do sexo realçado na figura masculina de Almeida Júnior.

No período que foi elaborada a obra em questão, a AIBA, possuía algumas regras para a representação da nudez nas obras, sendo que a licença concedida para que ocorresse tal representação só seria permitida caso o artista obedecesse às regras de distanciamento geográfico e temporal no que tange a elaboração da figura humana. Vale a pena salientar igualmente que a obra de Almeida Júnior - e mais especificamente a questão do corpo erótico masculino - surge no Brasil em um contexto particularmente rígido ao que diz respeito à moral e ao discurso higienista, no final de um século XIX ainda profundamente atrelado ao peso do jugo dos costumes sociais, enquanto o país inicia o seu processo de industrialização e modernização urbanística.

O artigo escrito por Afonso Sobrinho (2013), intitulado São Paulo e a Ideologia Higienista entre os século XIX XXX: a utopia da civilidade, aponta para a questão da necessidade que a burguesia daquele período tinha de desenvolver políticas higienistas nos centros urbanos a fim de afastar o estigma do "atraso dos trópicos" muitas vezes atrelado às condições de vida precárias da população mais pobre da sociedade, fazendo então que surgisse uma demanda pela limpeza das cidades e:

uma intervenção da ordem e disciplina das condições de vida e do próprio trabalho por meio da higiene pública. Utiliza-se dos discursos do progresso como uma utopia para que se possa disciplinar os espaços e corpos. Também a pobreza é associada às doenças causadas pela falta de higiene em moradias insalubres [...]. ${ }^{5}$

\footnotetext{
4 Cf. BARTHES, 1980

5 Cf. SOBRINHO, 2013, p. 2013, in: <https://seer.ufrgs.br/sociologias/article/view/38648/24790t>
} 
Os cortiços então, passaram a ser alvos diretos das políticas higienistas, pois eram neles que a sociedade burguesa via como um grande exemplo de um ambiente impróprio devido à insalubridade, doenças e o "desvio" das condutas morais. ${ }^{6}$

Derrubador Brasileiro, de Almeida Júnior, é uma obra executada durante sua estadia em Paris ou seja, ele estava distante de sua terra natal - e o modelo contratado para a elaboração da cena era italiano. O uso de um modelo estrangeiro para composição da cena indica a necessidade de "provocar" algumas situações que reforçam o esforço do pintor em criar uma narrativa visual, pela vontade de aproximar-se da ideia de uma brasilidade fora do país, uma vez que ele teve que lançar uso dos recursos da memória e imaginação para a elaboração da tela, tanto para a criação da paisagem quanto para a representação da figura humana. Mas é possível apontar uma força ambivalente em Derrubador Brasileiro, justamente no que se refere à sua capacidade de subverter a rígida convenção acadêmica, e consequentemente, o rígido moralismo que se sobrepunha à representação dos corpos durante este período.

Almeida Júnior, ao buscar sua temática no interior do país, acaba por manter um certo distanciamento espacial, assim como os artistas modernistas europeus buscavam no orientalismo o exotismo para a elaboração de uma obra que mantivesse um certo distanciamento entre o espectador e a obra7, no âmbito de representar então um nu "moralizante", ou tentar driblar a rigorosidade moral da academia. O pintor atrela-se - talvez de forma ingênua - à permanência do caráter exótico bastante presente da obra, e consequentemente ao distanciamento espacial ao retratar um homem interiorano, ligado à terra e a força braçal. O teor patriótico também se faz presente. Embora o artista tenha retratado uma figura anônima, sem grande importância histórica para o país, há um certo teor de identidade nacional na pintura, que é possível identificar tanto pela paisagem quanto pela própria figura masculina.

Mesmo que Almeida Júnior garanta certos níveis de distanciamento entre o espectador e a obra ao acrescentar o teor nacionalista em sua produção - o que caracterizaria uma adequação às regras de representação do nu na arte de seu período, possibilitando assim a inserção do que Bologne chamou de "véu de pudor"8-, ele ainda assim desafia as regras morais vigentes ao trazer para sua tela a imagem de lassidão do protagonista.

Alguns dos caminhos reflexivos possíveis sugeridos em Derrubador Brasileiro indicam que, se

\footnotetext{
6 Cf. SOBRINHO, 2013, p. 2014. In: <https://seer.ufrgs.br/sociologias/article/view/38648/24790>

7 Cf. BATISTA, 2011, in: <http://www.cbha.art.br/coloquios/2012/anais/pdfs/artigo_s2_stephaniedahnbatista.pdf.>

8 Cf. BOLOGNE, 1990
} 
Almeida Júnior acrescenta em algum momento o "véu de pudor", esse véu escolhido pelo artista parece ter sido demasiadamente (e talvez propositalmente) transparente.

Entre o erotismo e o bizarro no corpo nu masculino através de Alvim Corrêa

Segundo Alexandre Eulálio, 1981, a produção plástica de Henrique Alvim Corrêa desdobra-se em um amplo e complexo leque de expressões, o que torna sua produção singular na experiência cultural brasileira. Muito embora ele tenha sido um artista que teve toda a sua produção elaborada fora do país, Alvim Corrêa tem um trabalho que se destaca bastante em relação à produção artística nacional, pois como o observa José Américo Motta Pessanha, Henrique Alvim Corrêa foi "o mais explicitamente erótico entre os artistas brasileiros do período, não produziu para consumo local, entretanto sua obra hoje é uma baliza na História da Arte no Brasil"9.

A obra de Alvim Corrêa aqui analisada é uma aquarela de pequeno tamanho e faz parte da coleção Antônio Maluf conservada em São Paulo. É possível observar no primeiro plano, no canto inferior direito, uma pequena mesa acima da qual encontra-se uma garrafa de champanhe, uma taça e um charuto na beira da mesa. No lado oposto da mesa, há uma pequena caixa aberta, possivelmente uma caixa de cigarros ou de fósforos. No suporte inferior dessa mesa, encontram-se alocados um chapéu, um parde luvas, e uma bengala, bem à moda da época; esses trajes configuram o vestuário típico caracterizando o dândi, preocupado demasiadamente com sua indumentária,

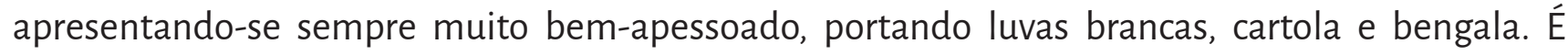
oportuno salientar aqui que a cartola, as luvas brancas e a bengala são elementos iconográficos atrelados à temática do dandismo na obra de Alvim Corrêa.

No segundo plano da composição da obra, é possível identificar a cama bagunçada com três pessoas em cima dela. De bruços, encontra-se uma mulher desnuda, mas ainda portando meias e sapatos, com um semblante relaxado. Ela apresenta um cigarro entre os dedos da mão direita, provavelmente ainda aceso, o que confere à cena um ar informal, onde o sexo pode ter surgido de maneira repentina e sem preocupações com a formalidade. Deitado acima das costas da mulher, encontra-se um homem cujo rosto é escondido por uma ampla massa de cabelos, demasiadamente musculoso e que assume o papel masculino, cuja representação do corpo, dos contornos acentuados da musculatura apresentam de fato uma modelagem quase caricatural. Seu braço direito en-

9 Cf. PESSANHA, 1991, p. 19 
volve sua parceira, a posição de sua mão que mais lembra uma garra, prende com força o corpo da mulher junto ao seu.

A diferença de postura dos personagens masculino e femininos nessa encenação, assim como a distribuição de ambos na composição remete a uma flagrante cena de iniciação à sexualidade, relembrando de passagem os panfletos ilustrando as obras do Marquês de Sade; enquanto a mulher deitada apresenta uma certa satisfação de gozo ou de prazer alcançado, marcada em seu rosto por um iniciante sorriso, seu corpo relaxado sem nenhuma rigidez ou tensão e o já mencionado cigarro aceso apenas reforçam o ar plácido da mulher; o suposto visitante - e possivelmente cliente regular da casa -, de corpo bastante robusto, exibe uma musculatura tensionada, como se fosse um último esforço físico. No lugar da cabeça da figura masculina, Alvim Corrêa retratou o que parece ser a cabeça de um animal, que não se define claramente como um felino ou um urso ou qualquer outro animal facilmente identificável; parecendo mais uma criatura fantástica, como uma espécie de minotauro, famosa representação antropomórfica da mitológica grega, formada por uma cabeça de touro com corpo de humano.

Ao mesmo tempo em que o artista carrega sua obra de fontes iconográficas da sua época - o que por sua vez rompem com o distanciamento espacial e temporal -, ao evocar o elemento subversivo em sua obra demasiadamente licenciosa, volta a acrescentar um certo distanciamento entre o espectador e a obra na medida em que ele não se prende rigorosamente a uma descrição realista de um ato sexual.

É possível perceber e entender nesse trabalho que as amarras do pudor, que se manifestavam através do distanciamento temporal e espacial, foram desatadas. Porém, será que há um resguardo do corpo masculino? Na presente obra de Henrique Alvim Corrêa, e nas demais obras do artista, de cunho erotizado, quando existe uma manifestação masculina, esta encontra-se muitas vezes mediada pela representação isolada do falo, e quando há a representação de um ato sexual entre um homem e uma mulher, como na obra em questão [fig. 2], o homem é representado como um ser fantástico em um corpo humano masculino dotado de uma cabeça animalesca, gerando assim um distanciamento mimético da representação da figura masculina, o que talvez esbarre nos limites impostos pelo pudor.

A ousadia em representar o erótico enquanto característica privilegiada do corpo feminino era uma prática comum retomada pelos artistas modernistas, mas o nu masculino, esse sim parece ainda vulnerável e se resguarda atrás do véu do pudor. Todavia, outro caminho interpretativo possível dessa obra [fig.2] diz respeito diretamente à figura masculina enquanto um ser antropozoomór- 
fico. A cabeça animalesca no corpo humano remete à figura fantástica do Minotauro, ser assustador da mitologia grega.

Assim posto, é possível então pensar que Alvim Corrêa, ao representar a figura masculina antropozoomorficamente em uma imagem próxima a um Minotauro talvez estivesse remetendo a o homem que, impulsionado pelo desejo e desprovido de razão, deva ser dominado. São inúmeras as possibilidades interpretativas das obras de Corrêa, especialmente no que se refere à diferenciação da representação da figura feminina e masculina.

\section{Considerações Finais}

Ambas as obras aqui analisadas, produzidas tanto por José Ferraz de Almeida Júnior quanto por Henrique Alvim Corrêa, nos apresentam figuras masculinas erotizadas; mas nos dois casos, o homem não tem a sua nudez exposta completamente - suas partes genitais são estrategicamente escondidas. Longe de terem sido expostos do mesmo modo como os corpos femininos costumavam ser naquele período quando o tema tinha uma relação mais ou menos estreita com a nudez na arte, as obras desses pintores que desafiaram a academia também parecem preservar algum pudor. No entanto, a força erótica (e a ousadia) em Derrubador Brasileiro ganha todo o seu poder sugestivo justamente pela figuração de um sexo ainda ocultado, mas muito bem ressaltado pela vestimenta; a carga erótica presente em Alvim Corrêa já se manifesta sem grandes artimanhas (mas também sem um completo mimetismo).

Todavia, essas obras, sempre inesgotáveis, sugerem algumas questões: por que os artistas, que pareciam ter em seu âmago um genuíno caráter desafiador da moral de seu período, tiveram tanta dificuldade (ou resistência ou autocensura) em representar o corpo masculino nu? E por que, hoje, a representação - ou simples menção - do elemento fálico, ainda nas práticas artísticas contemporâneas se revela um território tão sensivel e objeto alvo de censura? Esse breve mergulho neste estudo busca, tornar explícitas as indagações sugeridas pelas obras ao tratar e refletir alguns dos mecanismos, estratégias estéticas e das temáticas mais tradicionais no campo epistemológico da História da arte: o corpo e sua potência erótica. 


\section{Referências Bibliográficas}

BATISTA, Stephanie Dahn. Tendências, tabus e transgressões: As academias na Academia Imperial de Belas Artes. Artigo disponível em: http://www.cbha.art.br/coloquios/2012/anais/pdfs/artigo_s2_stephaniedahnbatista.pdf. Acesso em: 06/2018

BATISTA, Stephanie Dahn. O Corpo Falante: Narrativas e Inscrições num Corpo Imaginário na pintura acadêmica do século XIX. Artigo disponível em:<http://www.dezenovevinte.net/obras/corpo_academia.htm>. Acesso em: 06/2018.

BARTHES, Roland. A câmara clara: nota sobre a fotografia. Rio de Janeiro: Nova Fronteira, 1984.

BOLOGNE, Jean-Claude. A História do Pudor. Rio de Janeiro: Elfos Editora, 1986.

CHILVERS, Ian. Dicionário Oxford de arte. São Paulo: Martins Fontes, 2011.

EULÁLIO, Alexandre. Henrique Alvim Corrêa: guerra e paz. Cotidiano e imaginário na obra de um pintor brasileiro no 1900 europeu. In: Literatura e Artes Visuais. Rio de Janeiro: Fundação Casa de Rui Barbosa, 1981.

GULLAR, Ferreira. 150 anos de pintura no Brasil: 1820-1970. Rio de Janeiro: Colorama, 1989.

GOMBRICH, Ernst. A História da arte. [16 ed.] Rio de ]aneiro: LTC, 1995.

HAYECK, Thais Fernanda Martins. Alvim Corrêa e suas Mulheres Desnudas. Artigo disponível em:http://www.unicamp.br/chaa/rhaa/atas/atas-IEHA-v3-178-185thais\%2ofernanda\%2omartins\%2ohayek.pdf>. Acesso em: 06/ 2018.

MICLIACCIO, Luciano. A arte no Brasil entre o Segundo Reinado e a Belle Époque. In: BARCINSKY, Fabiana Werneck (org). Sobre a arte brasileira: da Pré-história aos anos 1960. São Paulo: WMF Martins Fontes/Editora SESC São Paulo, 2014, pp. 174-231.

PESSANHA, José Américo Motta. "Despir os nus". In: Leite, Cássio de Arantes (ed.) . O desejo na Academia: 1847-1916. São Paulo: Pinacoteca do Estado, 1991, pp. 43-51.

SANTOS, Alexandre. Indisciplina do desejo: Notas sobre a representação do corpo masculino na fotografia. In: STREY, Marlene Neves \& CABEDA, Sônia T. Lisboa (Org.). Corpos e Subjetividades em exercício interdisciplinar. Porto Alegre, EDIPUFRGS, 2004.

SOBRINHO, Afonso. São Paulo e a Ideologia Higienista entre o Século XIXe XX: A utopia da civilidade. Disponível em: <https://seer.ufrgs.br/sociologias/article/view/38648/24790>. Acesso em: 06/2018. 